\title{
Sujeitos de Gênero ou Sujeitos ao Gênero?
}

\author{
Pimone expaxecida Lisniousti \\ Mestranda em Direito Cooperativo na Pós-Graduação de Direito da \\ Universidade Federal do Paraná.
}

\section{RESUMO}

Na busca de representatividade social, o movimento ferninista tentou unificar os discursos e os sujeitos do ferninino, através da categoria "mulheres". No entanto, a busca da unificação de uma categoria "mulheres" tem-se revelado controvertida, pois ela se apresenta como um fator transformador das relações entre homens e mulheres cujo efeito é a cristalização destas identidades. Ou seja, o gênero mulher depende de aspectos raciais, de classe, étnicos, sexuais, históricos e geográficos, que em cada situação revela uma nova identidade discursioamente constituída. Ao tentar encontrar urna identidade única, descobriu-se enfim que as mulheres não reconhecem entre si uma única característica comum a todas. O termo "mulheres", mesmo usado no plural, foi contestado enquanto significante estável, pois não deu conta de descrever e representar a diversidade dos sujeitos do feminino. Isto apresenta uma impossibilidade de definir "mulheres" como uma única categoria. Desta forma, é impossível separar a questão "gênero" de outras interseções políticas e culturais nas quais o termo é invariavelmente produzido e mantido. JUDITH BUTLER questiona a visão totalizante de uma categoria "mulheres" e as conseqüências de uma unificação do sujeito do feminino, como, por exemplo, a exclusão de sujeitos étnicos, raciais, sexuais e culturais. Ela apresenta um estudo considerando o conceito de identidade como um dos problemas centrais desta tentatioa de unificação e considera que para podermos superar os limites impostos pelas estruturas dominantes devemos formular uma crítica das categorias da identidade que as estruturas políticas engendram, naturalizam e imobilizam. Uma verdadeira política representacional exige das teorias feministas uma revisão de suas construções ontológicas do sujeito, assim como rever a necessidade de basear-se em uma única posição, freqüenternente questionada pelos sujeitos excluídos desta base única.

Palavras-chave: gênero, identidade, feminismo.
1

a história da luta feminista vemos que as mulheres lutaram por direitos iguais em relação aos homens e defenderam seus interesses dentro de um discurso político. Além disso, buscaram uma identidade única de mulher, pois a constituição de um sujeito do discurso feminista possibilitaria uma visibilidade às mulheres por meio da representação política desta identidade.

Esta identidade foi construída, segundo KEHL (2000), pela crescente produção literária feminina do século XIX, quando a mulher passou da posição exclusiva de objeto dos discursos médicos, teológicos, filosóficos, para a de sujeito do discurso.

Esta preocupação com a identidade do feminino está associada à idéia de igualdade em relação aos homens, mas ao mesmo tempo que o movimento feminista marca uma igualdade também busca marcar uma diferença.

A luta política tem como característica o conflito entre diferentes identidades. 
No movimento feminista este conflito entre diferentes identidades impulsionou uma busca pela identidade do feminino através de uma categoria "mulher" que representasse politicamente todas as mulheres. No entanto, as transformações na globalização colocam em evidência as identidades nacionais e étnicas, pois as "identidades em conflito estão localizadas no interior de mudanças sociais, políticas e econômicas, mudanças para as quais elas contribuem, (...), a luta e a contestação estão concentradas na construção cultural de identidades" (SILVA, 2000). E, nesta busca de definição de uma identidade universal que representasse as mulheres, o discurso feminista deixou de considerar as identidades questionadas atualmente.

Ao procurar definir a categoria "mulher", alguns autores voltaram-se para diferentes perspectivas. A perspectiva essencialista coloca a identidade como fixa, como algo inerente à pessoa, esta visão impõe uma fixidez histórica, a essência está para ser descoberta, pois a pessoa não se modifica. Numa perspectiva oposta, BEAUVOIR (in BUTLER, 1999) argumenta que "uma pessoa se torna mulher, não nasce mulher", ou seja, são possíveis inúmeras "construções" para a identidade e que, além disso, o gênero independe de ser um corpo feminino ou masculino. As várias concepções de gênero ampliam a discussão da identidade feminina, questionadas por JUDITH BUTLER em uma crítica a respeito do sujeito do feminismo.

Em seu livro Gender Trouble, JUDITH BUTLER afirma que:

"As teorias feministas, em sua maior parte, pressupõem a existência de uma identidade feminina, entendida através da categoria de mulheres. Esta categoria não apenas funda os interesses e objetivos feministas dentro do discurso, mas constitui o sujeito para o qual busca-se uma representação política." (BUTLER, 1990)

Ou seja, as feministas defenderam uma representação única para as mulheres para que, através desta identidade, pudessem conquistar uma visibilidade política. Mas política e representação são termos controversos, pois as representações individuais da identidade da mulher nem sempre são legitimadas dentro do discurso político do feminismo. A busca de representação política tentou universalizar as identidades, excluindo outras identidades de mulheres.

Isso aconteceu porque o discurso político submete-se às normas sociais para tornar-se visível e assim ser legitimado. Então, para que serve uma representação política que repete a exclusão de sujeitos que não se adaptam aos requerimentos da identidade hegemônica?

De acordo com BUTLER (1990):

"A representação serve, por um lado, como um termo operativo dentro de um processo político que busca estender a visibilidade e a legitimidade para as mulheres enquanto sujeitos políticos; por outro lado, a representação é a função normativa de uma linguagem que tanto revela quanto distorce o que é assumido como verdade sobre a categoria de mulher."

Ou seja, ao defender seus direitos enquanto sujeitos políticos, as mulheres buscaram representar sua identidade na sociedade, mas esta representatividade 
também exerceu uma função normativa ao estabelecer uma representação única para a identidade feminina. Esta identidade única, ao mesmo tempo que revela uma identidade para as mulheres, já aceita socialmente, também distorce e limita a inclusão da representação de outras identidades na categoria "mulher".

Para aumentar a visibilidade política das mulheres, a teoria feminista busca o desenvolvimento de uma linguagem que, totalmente ou adequadamente, represente "mulheres". Esta categoria "mulher", defendida no discurso feminista, é a busca pela construção de uma identidade e de uma linguagem que represente o sujeito feminino. Entretanto, ao observarmos a condição cultural que permeia a construção deste sujeito do discurso feminista, parece-nos óbvia a consideração de que as diferentes subjetividades e papéis das vidas das mulheres estão mal representadas ou não estão representadas de todo.

Ao lutarem por igualdade, entraram no mercado de trabalho como os homens, mas dentro de casa suas atividades não foram reconhecidas, assim como havia uma representação de mulher na qual não se incluía as mulheres homossexuais e ignoravam-se os preconceitos raciais. Assim, algumas mulheres, mesmo no movimento feminista, são consideradas mais cidadãs que outras.

\section{Mas, para JUDITH BUTLER} (1990), "recentemente, esta concepção prevalecente da relação entre a teoria feminista e as políticas tem sido desafiada pelo próprio discurso feminista". Ou seja, nesta perspectiva, nada mais do que se diga sobre o que é ser mulher considera-se estável e não pode ser compreendido em termos duradouros.

Existe um extenso material que questiona a viabilidade de "o sujeito" ser candidato para a representação de uma categoria, ou para sua liberação de fato. Mas nestes estudos existe pouca concordância sobre o que a categoria de mulheres constitui, ou deveria constituir. Como deveria ser representada a categoria "mulher", ou o que deveria constituir nela afim de ser representativa? Se não for possível a definição de um sujeito "mulheres" ao qual se refere o movimento, como será fundamentada a representação do sujeito do feminino?

Alguns parecem achar que os caminhos devem ser os mesmos seguidos pelas lutas feministas do século passado, outros negam que esta luta trará algum resultado positivo, pois pressupõe a delimitação do sujeito a uma única representação discursiva.

Buscando um passado supostamente comum a todas as mulheres, procura-se autenticar uma determinada identidade na luta política feminista. STUART HALL (1990 apud SILVA, 2000) pensa que a identidade cultural tem duas formas diferentes, assumidas pelos sujeitos que falam a partir de uma posição histórica e cultural específica. Uma procura recuperar o passado na sua "unicidade" e a outra vê a questão de como "tornar-se" e como "ser", ou seja, reconhece que, ao ser reconstruído, o passado sofre transformações. Segundo JONATHAN RUTHERFORD (in SILVA, 2000) “... a identidade marca o encontro 
de nosso passado com as relações sociais, culturais e econômicas nas quais vivemos agora... a identidade é a interseção de nossas vidas cotidianas com as relações econômicas e políticas de subordinação e dominação". Ou seja, as possibilidades de construções são variadas, se analisarmos a questão do ponto de vista da linguagem vemos que tanto a identidade quanto a diferença são construídas.

Ao ser representado política e lingüisticamente, os sujeitos já estão qualificados de uma certa forma que estabelece os critérios pelos quais se define que aquele é um determinado sujeito e não outro. Para ampliar a representação do sujeito e estender o entendimento acerca de sua condição é preciso "superar" a linguagem e a política dominantes para que este sujeito seja representado enquanto é, e não simplesmente enquanto o representam. Mas mesmo aqueles que lutam pela representação como sujeitos políticos ainda não sabem que posição tomar acerca das delimitações estabelecidas a si mesmos enquanto sujeitos da linguagem. O campo político e lingüístico no qual o sujeito é representado determina a escolha de um sujeito previamente delimitado.

“O domínio de 'representação' política e lingüística lança adiantadamente o critério pelo qual os sujeitos são formados, resultando no fato da representação ser estendida apenas para o que pode ser reconhecido como um sujeito. Em outras palavras, a qualificação em ser um sujeito deve primeiro ser encontrada antes que a representação possa ser estendida." (BUTLER, 1990)

É como tentar comunicar algo que ainda não foi dito, para ser compreensível discursivamente é necessário adaptar-se à linguagem, e a estrutura lingüística limita a expressão do vivido. Para SAUSSURE (in SILVA, 2000), a linguagem se constrói numa cadeia de diferenciação lingüística. Em sua concepção de linguagem, os conceitos só têm sentido se estão relacionados, um conceito é definido por aquilo que ele não é. Por exemplo: um "brasileiro" existe por não ser francês, chinês; e a palavra "brasileiro" é compreensível porque sua marca gráfica e fonética é distinta de outras palavras. $\bigcirc$ conceito de feminino existe por se distinguir de masculino, mas esta diferença não é somente gráfica e fonética, mas cultural e está limitada ao discurso tal como ele está estruturado.

Em relação à delimitação discursiva do sujeito, FOUCAULT afirma que "os sistemas jurídicos de poder produzem os sujeitos que eles subseqüentemente vêm a representar. Sendo que, as noções jurídicas de poder parecem regular a vida política em termos puramente negativos, ou seja, através da limitação, proibição, regulação, controle e mesmo 'proteção' de indivíduos relacionados com aquela estrutura política através das operações contingentes e retratáveis da escolha" (BUTLER, 1990).

Para FOUCAULT, a representação do sujeito totalizante só é possível dentro do sistema jurídico, uma vez que não há unicidade nos sujeitos políticos representados e vividos fora dele. Ou seja, para ser representado no sistema jurídico, todo o sujeito deve aceitar ser definido e, portanto, delimitado por esse sistema. Nesta visão, os sujeitos representados nos sistemas jurídicos são produzidos pelo próprio sistema, 
com todas as delimitações estabelecidas anteriormente por um pensamento hegemônico. $\bigcirc$ preço de ser aceito e representado pela estrutura política na qual está inserido é o de estar em concordância com os requerimentos e delimitações dadas ao sujeito nestas estruturas.

Desta forma, a representação feminina torna-se uma formação discursiva e jurídica do próprio sistema que a exclui. As delimitações lingüísticas respeitam a estrutura política dominante, e a representação das mulheres nesta formação discursiva é conseqüência de uma política representativa que, ao mesmo tempo que constitui as mulheres enquanto sujeito, as delimita a uma representação hegemonicamente masculina. Se esta análise está certa, então "a formação política e jurídica da língua que representa as mulheres como 'o sujeito' do feminismo é em si mesma uma formação discursiva e um efeito de uma dada versão das políticas representativas" (BUTLER, 1990).

Desta forma, pode-se dizer que o sujeito do discurso feminista é constituído pelo mesmo sistema político que supostamente possibilita sua emancipação. Esta questão apresenta-se problemática para a luta feminista, pois o sistema político hegemônico diferencia os sujeitos de gênero de acordo com um eixo de dominação e representa todos predominantemente enquanto sujeitos masculinos. Mesmo que o sistema político represente as mulheres, representa de forma a limitá-las a um discurso onde prevalece o masculino.

As práticas discursivas que demarcam os territórios dos corpos é baseada na diferença sexual; não simplesmente o diferente, mas sim uma norma que impõe uma condição estática aos sexos, a fim de serem conhecidos, controlados, produzidos. Se os corpos são diferenciados, torna-se necessário definir que diferenças são estas. Para FOUCAULT, a categoria "sexo" é o "ideal regulatório", ele é um conjunto de normas sociais que tanto afirma uma identidade quanto exclui outras, produzindo os corpos que governa. É através deste poder de regulação que é possível legitimar os corpos que ele produz, reafirmando uma generalização que ele próprio criou.

Portanto, construir um apelo emancipatório dentro deste sistema é inútil, pois a emancipação das mulheres não vai se dar dentro do sistema hegemônico que não a reconhece, e sim através de uma crítica a ele. Deste modo, discutir a emancipação feminista sem discutir o sistema político é aceitar a determinação de um sistema que primeiramente exclui e delimita sujeitos de acordo com um objetivo de dominação e verdade, subjugando as mulheres.

$\bigcirc$ fato de que não são todos os sujeitos que se conformam completamente demonstra a necessidade de que estas normas sejam constantemente reiteradas juridicamente e politicamente. E é esta instabilidade que comprova a possibilidade desta força regulatória voltar-se contra ela mesma, havendo uma inversão das normas, e através desta transformação enfraquecer o poder hegemônico de regulação. Mas isto não garante a mudança da dinâmica de regulação. Pode-se mudar as normas e permanecer o poder de regulação e da primazia de um 
sujeito político representando a totalidade dos diferentes sujeitos sociais. É através de uma análise desta produção social que se enfraquecerá o poder da norma regulatória.

\section{Segundo BUTLER (1990):}

"Embora os discursos políticos que mobilizam as categorias de identidade tendam a cultivar identificações a serviço de um objetivo político, pode ocorrer que a persistência da desidentificação seja igualmente crucial para a rearticulação da contestação democrática."

Talvez uma das formas de conquistar um espaço democrático na sociedade seja através da crítica à normatização, e não de inclusão de outros sujeitos à legitimação destas normas.

A constituição do "sujeito", afirma BUTLER, torna-se assim uma questão crucial para a política, e para a política feminista em particular porque os sujeitos representados politicamente são sujeitos jurídicos produzidos pelo sistema. E como tal, são representados por práticas exclusionárias que não explicitam como o jurídico e o político determinam essa representação. Neste sentido, ao legitimar a delimitação de certos sujeitos, a lei oculta sua tendência em representar exclusivamente os interesses dos sujeitos que ela reconhece, excluindo outros sujeitos. Esta exclusão está fundada em interesses políticos ocultados para que o jurídico represente o que ele próprio produz, e assim ele próprio se legitima.

Uma política que pretenda representar o sujeito do feminino deve ter consciência de sua função jurídica e produtiva do poder que termina produzindo os sujeitos que ela declara meramente representar. $\bigcirc$ discurso feminista deve estar consciente de que a lei atribui a si mesma este caráter de verdade e portanto toda afirmação que ela faz sobre o sujeito é no sentido de naturalizálo, sendo que, na verdade, ele é constituído como um sujeito de direito. Toda afirmação da lei é uma premissa que legitima sua hegemonia regulatória. Ao negar seu caráter cultural, a lei nega os sujeitos culturais que nela não se encontram representados.

Desta forma, buscando representar o sujeito como sendo anterior à lei, ela produz e oculta que produziu objetivando naturalizar o sujeito, com o estatuto de verdade de uma ciência. Ao naturalizar o sujeito, realiza a operação de legitimar a própria lei e sua função regulatória.

A busca da emancipação feminista encontra aí seu maior paradoxo ao procurar encontrar no discurso da política e da lei uma forma de tornar a mulher, o sujeito do feminismo, mais autenticamente representada. Entretanto, a emancipação feminista é buscada nas mesmas estruturas de poder que a restringem. Portanto, não basta às mulheres lutarem por representação política sem entender como a categoria "mulheres" é produzida pelas estruturas de poder que a domina. Só a partir deste entendimento será possível a busca da emancipação.

\section{Para BUTLER (1990):}

"A questão das mulheres como o 'sujeito do feminismo' levanta a possibilidade de que talvez não haja um sujeito que exista 'antes' da lei, esperando por 
representação dentro e pela lei. Talvez o sujeito, bem como a invocação de um 'antes' temporal, é constituído pela lei como a fundação fictícia de sua própria demanda por legitimação."

A existência de uma integridade ontológica do sujeito "antes" da lei é uma ficção das estruturas jurídicas no liberalismo clássico. Esta prerrogativa aponta para um sujeito pré-social, em um tempo não histórico onde as pessoas não conviviam socialmente com regras, num estado natural e que, em um dado momento, elas consentiram em serem governadas e portanto atribuíram às leis um caráter irrevogável, legitimando o contrato social que asseguraria o convívio. A partir desta premissa o sujeito originário deste primeiro contrato seria um sujeito no estado natural e portanto a lei essencialmente o representaria.

Ao lutar por seus direitos, as feministas constataram que o termo "mulheres" denota uma identidade comum que no entanto não abrange as demandas por representação de todas as mulheres. Apesar da noção de sujeito ser fundamentada por ficções fundadoras, a hipótese de que todas as mulheres são iguais tornou-se um problema político para o feminismo. Elas, ao lutarem por seus direitos, se viram colocadas em uma única categoria que não as representava politicamente em sua diversidade. Ao tentar encontrar uma identidade única, descobriu-se enfim que as mulheres não reconhecem entre si uma única característica comum a todas. $\bigcirc$ termo "mulheres", mesmo usado no plural, foi contestado enquanto significante estável, pois não deu conta de descrever e representar a diversidade dos sujeitos do feminino.
Ao analisar as identidades e sua universalização, KING afirma que "as identidades globalizadas marcam uma homogeneidade que podem distanciar as identidades locais de sua cultura, criando novas identidades ou podendo levar à resistência, fortalecendo identidades locais e nacionais" (SILVA, 2000). Este efeito foi sentido pelo movimento feminista que, ao generalizar uma identidade do feminino, impossibilitou a inclusão em seu discurso das demandas de mulheres de diversos contextos.

Existe uma multiplicidade de significações em relação ao termo "mulher". Se uma pessoa é uma mulher, certamente isso não é tudo que ela é. $O$ gênero designa algo que não é constituído coerentemente em diferentes contextos e de difícil definição. Ou seja, o gênero "mulher" depende de aspectos raciais, de classe, étnicos, sexuais, históricos e geográficos, que em cada situação revela uma nova identidade discursivamente constituída. Isto apresenta uma impossibilidade de definir "mulheres" como uma única categoria. Desta forma, é impossível separar a questão gênero de outras interseções políticas e culturais nas quais o termo é invariavelmente produzido e mantido.

Supõe-se que deva existir algo em comum na base universal do feminismo, uma identidade única transcultural. Esta suposição baseia a prerrogativa de que exista um tipo universal de patriarcado, de dominação hegemônica masculina.

Mas ao analisar situações concretas, a noção de um patriarcado universal não se afirma, pois cada opressão de gênero pare- 
ce se originar de diferentes formas e assume significados diferenciados nos contextos culturais concretos onde ela existe.

A prerrogativa de uma base universal para a dominação masculina é tão sedimentada que algumas teorias a assumem sem refutar seu caráter ficcional. $\bigcirc$ que acontece normalmente é que estas teorias buscam nos diferentes contextos exemplos específicos, apenas com o intuito de exemplificar ou ilustrar suas hipóteses previamente assumidas como verdadeiras. A psicanálise, por exemplo, foi freqüentemente alvo de críticas por sua diferenciação hegemônica da identidade masculina em relação à feminina.

Muitas destas tentativas de teorização feminista procuram defender a tese de que a opressão de gênero é um fenômeno universal, sutilmente explicando-a como uma espécie de barbarismo essencial não ocidental. Esta construção de um "Oriente" ou de um Terceiro Mundo é amplamente criticada, pois tenta se apropriar e colonizar as culturas orientais, imprimindolhes concepções ocidentais de opressão, para depois responsabilizá-las por uma espécie de essência bárbara.

Segundo KING (SILVA, 2000) o Ocidente construiu uma idéia do Oriente "que diz mais sobre os medos e as ansiedades ocidentais do que sobre a vida do Oriente". Podemos pensar então que a construção do sujeito do feminino pelo discurso hegemônico masculino diz muito mais respeito aos homens do que às mulheres.

A busca feminista em estabelecer um denominador comum para o patriarcalismo e portanto uma identidade feminina compartilhada por todas as mulheres tem feito com que apressadas conclusões a respeito de uma suposta dominação masculina universal apareçam a fim de fundamentar uma demanda por representatividade feminina.

Foi difícil retirar a crença de que exista uma universalidade na dominação masculina. Mas tem sido muito defendida a idéia de que existe uma identidade feminina compartilhada, por ser ela o núcleo central das abordagens teóricas feministas.

BUTLER (1990) analisa as afirmações do discurso feminista com o mesmo enfoque dado ao discurso dominante, levantando várias questões sobre esta identidade feminina compartilhada universalmente.

A mesma crítica à dominação colocada pelo feminismo é repetida quando, no caso de algumas feministas que tomam como base a "identidade e as qualidades singulares das mulheres... em favor de um separatismo relativamente aos homens... (por exemplo, o) papel biológico das mulheres como mães as torna inerentemente mais altruístas e pacíficas... (justificando assim) uma história exclusiva das mulheres" (SILVA, 2000).

Estas posições de dominação não são exclusivas dos homens, mas estão permeadas pelos discursos que muitas vezes pretendem emancipar uma minoria.

Se as mulheres compartilham alguma ligação, esta estaria vinculada à sua opressão, ou existe algo anterior à opressão que as vincule de alguma forma? 
A busca por um sujeito estável do feminismo, através de uma categoria de mulheres, tem gerado várias resistências. A dificuldade generalizada de aceitação da categoria "mulher" deve-se ao fato de que esta categoria é pensada em um discurso de polaridade entre o dominador e o dominado. A unidade e a universalidade buscadas para esta categoria estariam ligadas à posição de um feminino ainda submetido à hegemonia masculina e não como uma categoria independente da ação do masculino. A busca de unidade, desta forma, termina por reproduzir a relação de dualidade e o discurso dominante.

"Existe algo em comum nas culturas das mulheres que seja independente da influência das culturas masculinas hegemônicas? O que especificamente diferencia as mulheres em cada cultura e o que entre elas é comum, independente da interferência masculina opressiva? As práticas culturais e lingüísticas estritamente femininas apresentam especificidade e integridade próprias ou aparecem sempre ligadas a formações culturais mais dominantes? São elas construídas culturalmente contra e, especificamente, em relação à dominação masculina?" (BUTLER, 1990).

A especificidade do feminino não é reconhecida exclusivamente pela abordagem do binário masculino/feminino, mas por outras formas de especificidades. A categoria "mulheres" é descontextuada e separada de outras relações sociais, econômicas, políticas e culturais como, por exemplo, a profissão, nacionalidade, raça, etnia, etc.

Por que a insistência na busca de um sujeito do feminismo geraria múltiplas re- cusas à constituição de uma tal categoria? A fim de representar as mulheres, a tentativa de construção de um sujeito do feminismo utiliza-se de uma categoria previamente estabelecida e que não representa todas as mulheres. Mesmo para fins emancipatórios, a construção desta categoria implica exclusão, pois, ao regular as relações e impor uma representação da mulher, esta categoria termina por não compreender a todas as mulheres.

A recusa das mulheres em se identificarem com uma única categoria revela o paradoxo de um discurso feminista que pretende representá-las. Esta oposição sugere a necessidade de uma maior preocupação com uma política da identidade.

Se esta representação não for ampliada, as declarações que o feminismo imputa ao sujeito que ele busca construir e representar estão fadadas ao fracasso. Para ampliar esta representação é preciso considerar os poderes constitutivos das declarações deste discurso feminista.

Resolver este problema justificando que a definição da categoria "mulheres" tem somente objetivos estratégicos não impede as conseqüências prejudiciais de exclusão dos sujeitos que não se enquadram nestas representações. Segundo BUTLER (1990) "as estruturas jurídicas da linguagem e das políticas constituem o campo contemporâneo do poder; e portanto, não há posição política fora deste campo, mas apenas uma genealogia crítica de suas próprias práticas legitimadoras".

Para poder superar os limites impostos pelas estruturas dominantes, devemos 
formular uma crítica das categorias da identidade que as estruturas políticas engendram, naturalizam e imobilizam. Uma verdadeira política representacional exige das teorias feministas uma revisão de suas construções ontológicas do sujeito, assim como rever a necessidade de se basear em uma única posição, freqüentemente questionada pelos sujeitos excluídos desta base única.

Esta unificação pode ser reguladora e reificadora das relações de gênero e não representativa como se pretende. A política feminista necessita contestar esta identidade estável por uma identidade variável, pois se a categoria "mulher" só encontra estabilidade e coerência no contexto heterossexual então esta noção estável de gênero não consegue mais ser eficaz. E esta noção feminista será um pré-requisito metodológico, normativo e do seu objetivo político.

Esta genealogia feminista da categoria "mulheres" tem como objetivo político descobrir como se produz e se oculta as características do sujeito jurídico do feminismo. Questiona-se com isto a viabilidade de uma categoria "mulher", assim como sua possibilidade de representação política.

Afinal, a representação política de um sujeito do feminismo se dá pelo sacrifício de outros sujeitos que não se adaptam, não se conformam com os requerimentos normativos desta política representativa e exclusivista. Pode-se pensar que, quando o foco político é unicamente a representação, ele sustenta diferentes formas de dominação e de exclusão. Então, para ser representativo, o discurso feminista não deve pretender universalizar a categoria "mulher".

A identidade do sujeito do feminismo se fundou num campo de poder para depois tornar-se a fundamentação da política feminista. Sua legitimação está fundamentada no campo do poder assim como seu argumento passa a ser o fato de que estaria representando o sujeito feminino. Mas, seria possível uma representação que faça sentido para o feminismo ou todas estariam fundamentadas em discursos de poder? Para BUTLER (1990) isto talvez aconteça “quando o sujeito de 'mulheres' não for presumido de forma alguma”. Isto é paradoxal pois uma identidade que pretenda se legitimar busca uma característica em comum, presumindo que todas as mulheres a possuam.

Como podemos unificar este sujeito, mesmo teoricamente, se ele é dividido pela ruptura entre sexo e gênero? Supõe-se que o gênero seja culturalmente construído em oposição ao sexo que é determinado biologicamente. Assim, segundo BUTLER "levado ao seu limite lógico, a distinção entre sexo e gênero sugere uma descontinuidade radical entre corpos sexuados e gêneros culturalmente construídos". Ou seja, se gênero não depende de uma determinação biológica, então o binário que existe no corpo, masculino e feminino não é necessariamente seguido pelo gênero, podendo este ser múltiplo. Nesta multiplicidade de combinações, gêneros masculino e feminino poderiam se referir tanto a um corpo masculino quanto a um corpo feminino.

É a partir desta discussão gênero/sexo que BUTLER pretende encaminhar suas 
conclusões a respeito da identidade do sujeito do feminismo.

BUTLER levanta outro grupo de problemas para esta questão. Como podemos falar de um gênero sem saber exatamente a quê este gênero se refere? E o sexo, o que é? $\bigcirc$ que a ciência médica nos diz: que é hormonal, anatômico, cromossômico..., e o que a crítica feminista tem a falar sobre esta verdade dos especialistas da medicina? $\bigcirc$ sexo também possui uma história? Existe uma explicação para a sua divisão binária? Talvez o sexo seja tão construído quanto gênero, então estes dois não serão tão distintos assim. O sexo não é uma concepção jurídica, um dado natural, onde o gênero simplesmente inscreve-se culturalmente. $\bigcirc$ gênero é um instrumento discursivo através do qual se estabelece o sexo como um pré-gênero, um estado natural. $\bigcirc$ sexo é um vazio onde a cultura atua, e sua estrutura binária é de um domínio pré-discursivo, então o que se entende por sexo é produzido pelo discurso cultural do gênero? Por que o gênero tem que incorporar as relações de poder produzidas pela idéia de um sexo prédiscursivo e depois ocultar esta operação? Isto parece simplesmente um instrumento para justificar uma relação de dominação, e naturalizá-la a fim de legitimar-se.

Assim como o contrato social, o gênero descobre-se como uma ficção a fim de validar uma cadeia de significantes e dar sustentação ao seu próprio discurso.

A construção que está implícita no conceito de gênero é determinada socialmente ou tem infinitas possibilidades de transformação?
Para SOARES (2000:17) identidade "trata-se da síntese do ser, constituída democraticamente, livre dos condicionantes de valor de uso e de troca. Etapa caracterizada na educação infantil, prolongada na juventude e consolidada na fase adulta. É o resultado de um processo no qual o respeito pelas manifestações naturais, a permissão para sua consolidação, incentivo ao desenvolvimento aprimorado e original se efetiva".

A questão da preservação da identidade como uma questão essencialmente ecológica do ser colocada por SOARES entra diretamente em embate com a posição de BUTLER de que esta construção de identidade foi causa de imputação do sujeito. Para SOARES a constituição do sujeito deveria ocorrer sem obstáculos, enquanto para BUTLER o sujeito se vê impossibilitado de se manifestar em toda a sua potencialidade, e seu processo de constituição está condicionado à linguagem. Para SOARES é possível uma identidade livre dos sistemas de opressão, para BUTLER é da constituição do sujeito a impossibilidade de liberdade, pois a linguagem o limita.

SOARES diz que esta identidade pode estar aprisionada nas demandas sociais exigidas, onde "o ser contemporâneo está submetido às regras dos modelos de produção, da relação de classe e suas possibilidades de sucesso no mercado" (SOARES, 2000:25), homens educados para serem úteis, mas a significância e o significado desta palavra podem estar diluídos antes de se tornarem concretos.

"A essência que exibem não é a sua, é emprestada, quase sempre imposta 
a eles por outro indivíduo ou sociedade mais forte que os submete. Assim, a essência de tais seres está deslocada, eles são estranhos (alheios) a ela, ao que deveriam ser, perdem por isso a condição, a dignidade antropológica, existencial de sujeitos de si, tornando-se objetos de outro." (PINTO, 1991 apud SOARES, 2000)

Para BUTLER, o corpo aparece como passivo frente às marcas culturais, e ela também questiona se essa cultura pode ser entendida como um conjunto de leis. Entendido desta forma, o gênero poderia estar determinado pela cultura de forma tão fixa quanto o sexo é determinado biologicamente, do contrário, o gênero seria tão mutável quanto uma escolha.

Esta dificuldade parece, segundo BUTLER (1990), originar-se de uma controvérsia filosófica entre os significados de livre escolha e determinismo. "Como conseqüência, podemos suspeitar com razão que algumas restrições lingüísticas comuns no pensamento tanto formam quanto limitam os termos do debate" (BUTLER, 1990).

Os conceitos e categoria com os quais lidamos estão tão determinados culturalmente quanto a própria categoria de gênero?

BUTLER faz uma crítica à psicanálise por esta reiterar a organização e a normatização da heterossexualidade, enfatizando a relação heterossexual e a evidência da masculinidade. Esta interpretação crítica não invalida a contribuição da psicanálise para o estudo da feminilidade.

Segundo LACAN, o sujeito é estruturado como uma linguagem, ele se sujeita a ela a fim de se tornar um falante, e é através da linguagem que se materializa o corpo. A dificuldade em encontrar o sentido originário é causa de uma ruptura no sujeito, ruptura que limita os significados mas que possibilita a transformação, a resignificação, a invenção de si mesmo. Este mesmo sujeito que é limitado pela linguagem pode, através dela, romper limites.

Se esta for a visão reconhecida pela cultura, poderá a identidade feminina finalmente compreender todas as mulheres e representá-las politicamente? Seria inviável uma construção de gênero que diferisse das formulações já existentes pela totalidade efetiva de sua categoria? É possível delimitar e definir, a fim de representar, um sujeito político que abranja todas as subjetividades?

Esta mesma teoria que visualiza inúmeras subjetividades contém análises freqüentemente criticadas pelos movimentos feministas pelo seu caráter de supremacia do masculino.

Para FREUD, é o homem que sustenta a diferença sexual, pois é o homem o responsável pelo pacto civilizatório, enquanto a mulher é o objeto da disputa e a causa da proibição do incesto. $\bigcirc$ pai original não permitia aos filhos nenhum prazer, então os filhos assassinam o pai e fundam as leis, e estas leis só cairão se não cumprirem seu papel de possibilitar a satisfação dos filhos. Em "A Mulher e a Lei", KEHL apresenta a visão da psicanálise sobre as diferenças entre a ética feminina, que procura o prazer, e a masculina, que procura evitar o desprazer. No homem, a resolução do complexo de Édipo se dá pela substituição 
"do pai tirânico pela lei do pai: 'Você pode ter tudo que o pai tem, menos a sua mulher"” (KEHL, 1992).

Ou seja, nesta visão psicanalítica há uma nítida diferenciação entre o masculino e o feminino a partir de éticas distintas, mas não apresenta que estas distinções estejam ligadas ao corpo. Apesar de FREUD fazer esta ligação colocando a mulher no lugar de castrada por não possuir um falo materializado no pênis, a maioria dos psicanalistas defendem a idéia de que este falo é muito mais imaginário, podendo tanto o homem quanto a mulher fazer uso deste lugar.

\section{Em “A Mulher e a Lei", KEHL (1992)} apresenta a diferença freudiana da ética. A afirmação de FREUD é de que a mulher tem pouco compromisso ético enquanto que o homem funda o pacto social. $O$ filho está sujeito à ética paterna ao identificar-se com o pai e, de acordo com esta lei, só é dada a liberdade de ser sujeito àquele que aceita as leis estabelecidas socialmente. Mas a mulher não tem nada a temer, ela pode se identificar com a mãe sem reservas, a mãe não a ameaça, e portanto a lei ainda não se inscreveu. Só quando a menina busca a identificação com o pai é que ela vive a lei paterna através da recusa do pai em se identificar com uma castrada. Para a menina, qualquer identificação com o pai é um ganho, ela não precisa aceitar a lei paterna para se identificar, o máximo que ela pode perder é sua feminilidade, e perder a mesma exigência de amor incondicional que adquiriu ao se identificar com a mãe. Assim, a criança obedece à lei que mais promete satisfação pulsional.
O lugar do feminino na visão freudiana parece ser o mais desprezível, o lugar da falta, lugar do não ser, uma posição que sacrifica o sujeito (homem ou mulher) a favor do amor incondicional.

O homem foge de qualquer identificação com a mulher por fugir deste lugar de ser castrado, mas promete satisfazer a necessidade de amor incondicional ao aceitar a mulher como parceira sexual. Assim, a mulher apresenta-se como castrada para manter a imagem da masculinidade viril, ou seja, a ficção da relação sexual, e submetese ao outro para assim ganhar alguma identificação com o masculino.

Atualmente, para KEHL (2000) este lugar de objeto ocupado pela mulher para que o desejo do homem se manifeste não é encarado em sua face de masoquismo erógeno, lugar onde um dos parceiros destitui-se do lugar de falicidade, de detentor de um falo imaginário, para dar lugar ao desejo. Este lugar pode ser ocupado alternadamente pelo homem ou pela mulher, mas a ausência de um sujeito no "lugar do faltante" impede a satisfação do desejo. A mulher se identificou com a posição masculina, assim como o homem com a feminina, mas isto não lhes garantiu uma satisfação mais plena, pois a satisfação necessita do reconhecimento da falta e não apenas da troca alternada de papéis masculinos e femininos.

Este dilema manifesta-se moralmente para as mulheres. $O$ lugar do feminino não é tão vivido na relação sexual, pois a mulheres obrigam-se a descobrir o que devem fazer para agradar, descobrem como se fazer necessárias, mas não como se fazer 
desejadas. Isto talvez ocorra porque nem homens, nem mulheres querem mais ocupar este lugar de faltante, um lugar sem reconhecimento e sem representatividade.

\section{Referências bibliográficas}

BUTLER, Judith. Gender Trouble. Londres: Routledge, 1990.

KEHL, Maria Rita. "A Mulher e a Lei". In NOVAES, A (org.). Ética. São Paulo: Companhia das Letras, Secretaria Municipal de Cultura, 1992: 261273.
. "Psicanálise, Estudos Feministas e Gênero - sexualidade recontextualizada". In http:/ /www.psicomundo.com/foros/genero/ sexualidade.htm São Paulo: Conferência apresentada no Ciclo de Debates da Exposição Freud em 25.11.2000.

SILVA, Tomaz (org.), Stuart Hall \& Kathryn Woodward. Identidade e diferença: a perspectiva dos estudos culturais. Petrópolis, Rio de Janeiro: Vozes, 2000.

SOARES, Suely Galli. Arquitetura da Identidade: sobre educação, ensino e aprendizagem. São Paulo: Cortez, 2000. 